\title{
PHENOTYPIC DIMENSIONS OF REPRODUCTIVE ISOLATION BETWEEN NORTHERN AND MELISSA BLUE BUTTERFLIES IN THE ROCKY MOUNTAINS
}

\author{
ZACHARIAH GOMPERT $\uparrow$ UNIVERSITY OF WYOMING $\uparrow$ LARAMIE
}

\section{$\downarrow \quad$ INTRODUCTION}

Biological diversity results from speciation, which generally involves the splitting of an ancestral species into descendant species due to adaptation to different niches or the evolution of reproductive incompatibilities (Coyne and Orr 2004). The diverse flora and fauna of the world, including the native inhabitants of the Greater Yellowstone Area (GYA), exist as a result of the speciation process. The central role speciation plays in generating biological diversity imbues importance to our understanding of this process. The general importance of a thorough understanding of speciation is amplified because of the current high rates of extinction on the planet. This is because a long term solution to the present extinction crisis will require maintaining the processes that create species (speciation) not simply preventing extinction. However, many central questions regarding speciation remain to be answered. One fundamental question in speciation research is whether diverging species are isolated (i.e., prevented from interbreeding) due to differences in one, a few, or many characters and whether each of these character differences results from different alleles at a few or many genes. For example, speciation and reproductive isolation might involve divergence along multiple phenotypic axes, such as mate preference, habitat use or preference, and phenology (the timing of life-cycle events). Alternatively, isolation could result from differentiation of a single character. I propose to address this question by assessing patterns of variation for a suite of characters across a hybrid zone between two butterfly species. This is possible because patterns of character variation across hybrids zones allow for inferences about reproductive isolation (Barton and Hewitt 1985).
The habitat diversity and geographic location of Grand Teton and Yellowstone National Parks provide an ideal opportunity to study speciation and hybrid zones. The topographic diversity of these parks allows a variety of different habitats (e.g. mountain forests, arid plains, meadows, alpine zones, etc.) to occur in close physical proximity. This feature allows for incipient species that have adapted to different habitats to come into contact, which provides the opportunity to study the morphological, behavioral, and genetic changes that partially isolate incipient species. The situation for studying speciation in Grand Teton and Yellowstone National Parks is further improved because these parks occupy a geographic region of North America where the ranges of many recently or incompletely reproductively isolated species overlap. This is because many incipient species that diverged in eastern and western glacial refugia during Pleistocene ice ages have since shifted their ranges to the Rocky Mountains.

My project focuses on a specific pair of incipient butterfly species, the Northern Blue butterfly (Lycaeides idas) (Figure 1) and the Melissa Blue butterfly (Lycaeides melissa), that have come into contact in the GYA following the retreat of Pleistocene glaciers (Gompert et al. 2010). These are small butterflies in the Lycaenid family that are notable for the iridescent blue color on the dorsal surface of male wings. The Northern Blue is found in moist meadows and forest clearings from Alaska to the Rocky Mountains, whereas the Melissa Blue is found in more arid environments such as prairies and shrub-land throughout the western United States. These butterflies have several subtle differences in morphology and feed on different larval host-plants 
(Gompert et al. 2010). In the GYE, Northern Blue populations have a single generation per year with adults active from mid-July to early August; Melissa Blue populations have at least two generations per year with adults active in June or early July and again in late July or August (Z.G. personal observation, summer 2008 and 2009). My previous work demonstrated that Northern Blue and Melissa Blue butterflies interbreed in this region and have formed a hybrid zone (Gompert et al. 2010). This hybrid zone between the Northern and Melissa Blue is an ideal system to address the question of whether a few or many characters are typically involved in reproductive isolation.

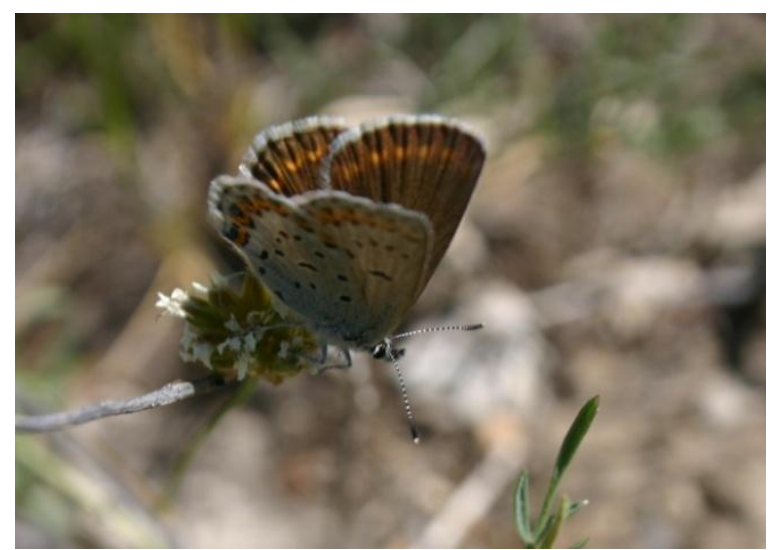

Figure 1. Photo of Northern Blue butterfly (Lycaeides idas)

The objective of this project is to identify specific characters that contribute to isolation between Northern Blue and Melissa Blue butterflies and determine whether these constitute a few or many characters. I was focusing on the following characters: male genitalic morphology, wing pattern morphology, male mate preference, female oviposition preference, diapause emergence conditions, and diapause initiation conditions. Data from morphological characters have been previously reported and published (see Gompert et al. 2010 for details). For each character, I will first determine whether differences exist between Northern and Melissa Blue butterfly populations. Characters that do not differ are unlikely to contribute to reproductive isolation. Character differences were assessed using a series of field and lab experiments coupled with Bayesian parameter estimation. For those characters that differ between Northern and Melissa Blue populations, we will also collect experimental data across the hybrid zone. We will contrast the geographic pattern of variation across the hybrid zone for each of these characters with the pattern of variation for neutral genetic markers using analytical methods derived from geographic cline theory (Barton and Hewitt 1985). Characters with significantly narrower geographic transitions between Northern Blue-like and Melissa Blue-like than expected given patterns of neutral molecular markers will be identified as likely being involved in reproductive isolation. The number of characters with geographic patterns of variation that indicate a potential contribution to reproductive isolation will provide a preliminary answer to the question of whether these species are isolated by a few or many characters. Because these butterfly species still hybridize, the estimate of the number of characters involved in isolation will underestimate the number of characters necessary for isolation between these species to be complete. The proposed research will be followed by extensive genetic mapping of these characters and population genetic analyses to verify these results.

\section{$\uparrow \quad$ METHODS}

We assayed male mate preference in two Melissa Blue populations (Lander, WY lat: $42.65^{\circ} \mathrm{N}$ long: $108.36^{\circ} \mathrm{W}$; Victor, ID lat: $43.66^{\circ} \mathrm{N}$ long: $111.11^{\circ} \mathrm{W}$ ), two Northern Blue populations (Bunsen Peak, WY lat: $44.93^{\circ} \mathrm{N}$ long: $110.72^{\circ} \mathrm{W}$; Siyeh Creek, MT lat: $48.77^{\circ} \mathrm{N}$ long: $113.72^{\circ} \mathrm{W}$ ), and four populations from the Rocky Mountains hybrid zone (Bull Creek , WY lat: $43.30^{\circ} \mathrm{N}$ long: $110.55^{\circ} \mathrm{W}$; Blacktail Butte, WY lat: $43.64^{\circ} \mathrm{N}$ long: $110.68^{\circ} \mathrm{W}$; Mt. Randolf, WY lat: $43.86^{\circ} \mathrm{N}$ long: $110.40^{\circ} \mathrm{W}$; Hayden Valley, WY lat: $44.68^{\circ} \mathrm{N}$ long: $\left.110.50^{\circ} \mathrm{W}\right)$. This was done by placing pairs of model females (made by printing high quality wing patterns from photographed butterflies) with Northern Blue and Melissa Blue wing patterns at each population in the presence of males searching for mates. The behavior of individual males was then recorded, specifically we recorded which model individual males approach. Similar experimental designs have been effective for testing male mate preference in butterflies (Jiggins et al. 2001, Fordyce et al. 2002). Approaching males were captured using insect nets and retained for future morphological and genetic analyses. We used Bayesian statistical models to estimate mate preference for each population and test for differences in this preference between Northern Blue and Melissa Blue populations.

We conducted oviposition preference experiments using wild-caught female Lycaeides from nine populations to determine whether females discriminated among potential host plants. Each experiment presented female Lycaeides with two (Sinclair, WY) or three (all other experiments) potential host plants. Medicago sativa was included 
in all experiments, as it was found near most sites. For each experiment, the host plant(s) used by the population were also included along with one or two other possible legume host plants from the genera Astragalus, Lupinus, or Oxytropis, which are known to be fed on by Lycaeides (Scott 1986). We identified the host plant(s) used by a population based on direct observation of female oviposition, observations of larval feeding, or an association of adult butterflies with the plants in the field. Host plant material was collected at or near each population, and only fresh host plant material was used. All collected plants were deflowered to control for known effects of the presence of flowers on female oviposition preference in Lycaeides (Forister et al. 2009). Females were collected during the July and August of 2009 and 2010. Females were placed singly in small plastic oviposition chambers, constructed from plastic drinking cups covered with bridal veil. A few sprigs of host plant material for each plant were placed through small holes in the bottom of oviposition chambers so that their stems had access to a common water reservoir. Female butterflies were fed Gatorade ad libitum as an artificial nectar source, which was applied directly to the bridal veil. After approximately 48 hours female butterflies were removed from the oviposition chambers and the number of eggs on each host plant species was counted. This experimental design has been used successfully in the past to study oviposition preference based on short-range cues (not long range cues such as plant architecture) in other Lycaeides populations and other Lycaenid butterflies (Gompert et al. 2006).

We conducted a second series of oviposition preference experiments to determine whether differences in oviposition preference might contribute to reproductive isolation between $L$. idas and $L$. melissa. We designed and carried out these experiments as described in the preceding paragraph, but with a few modifications. For each experiment we used only two host plants: $M$. sativa and $A$. miser hylophilus. The former is the host plant of many populations, whereas the latter is used by most $L$. idas populations in Wyoming and southern Montana as well as many admixed population (ZG personal observation). By using this pair of host plants we were able to contrast oviposition preference of each population between common L. idas and L. melissa, which provides a metric of the extent that differences in oviposition preference serve as a barrier to gene flow. Additionally, by using a common pair of host plants across all tested populations we were able to more easily compare results among populations.
These experiments were conducted in the summer of 2010 between July 4 and August 14 and involved 12 populations ( 3 L. idas, 3 L. melissa, and 6 admixed).

\section{$\uparrow \quad$ RESULTS AND DISCUSSION}

Many populations discriminated among potential host plants, although some but not all populations preferred their native host plant (Figure 1). For example, L. melissa from Sinclair have a strong preference for their native Astragalus, whereas Siyeh Creek females prefer to lay eggs on Medicago sativa which is not a host plant used by this population.

Figure 1. Probability of a female for different populations laying eggs on each of two or three host plants. Population
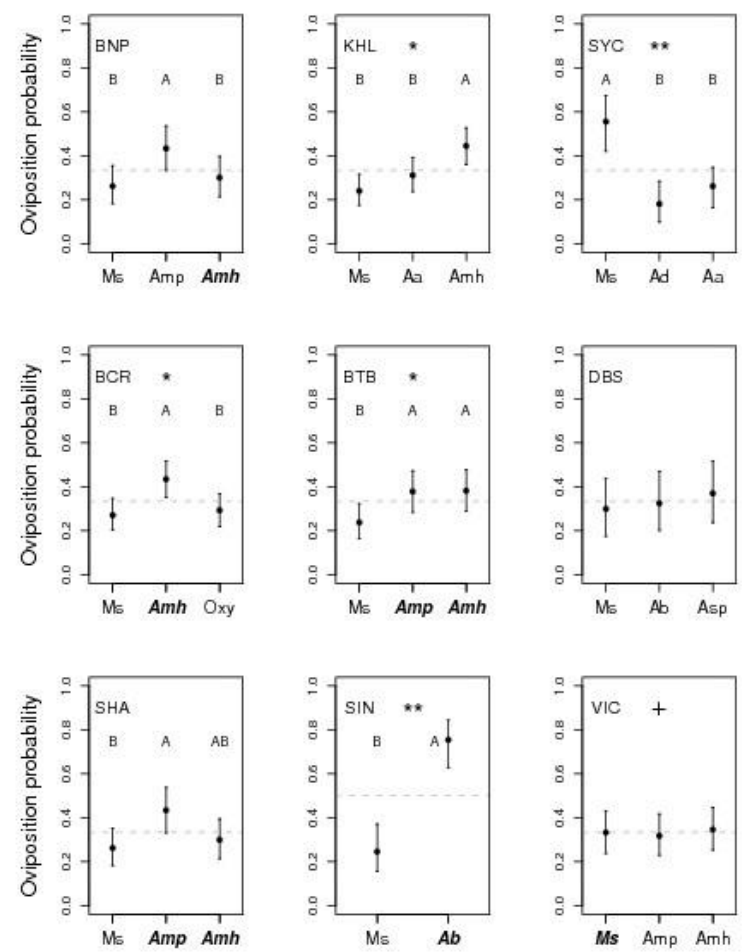

abbreviations are Bunsen Peak, WY (BNP), Kings Hill, MT (KHL), Siyeh Creek, MT (SYC), Bull Creek, WY (BCR), Blacktail Butte, WY (BTB), Dubois, WY (DBS), Shadow Mountain, WY (SHA), Sinclair, WY (SIN), and Victor, ID (VIC). Host plants include Medicago sativa and several species of Astragalus. The native host plant(s) for each population is(are) in bold type.

Lycaeides idas males generally approached $L$. idas female wing models more often than $L$. melissa wing models (Figure 2A), whereas Lycaeides melissa males generally approached L. melissa female wing models more often than $L$. idas wing models. Nonetheless males from each species readily 


\section{A. Population-level male mate preference}

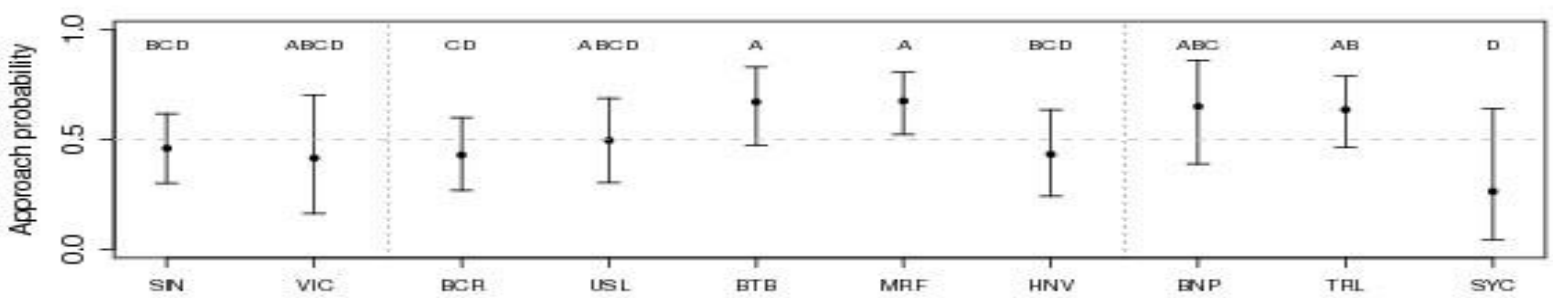

B. Sexual isolation from male mate prefernce

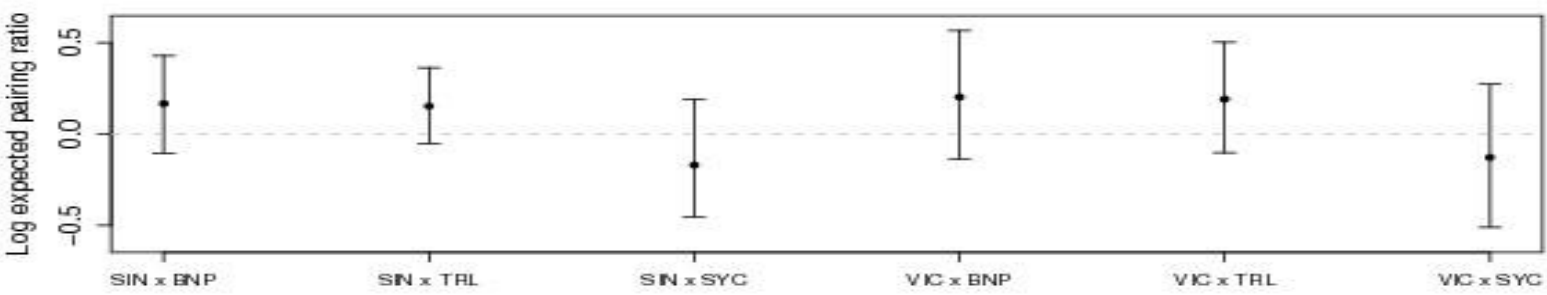

Figure 2. Relative probability of males approaching L. idas wing models (A). Population abbreviation are given in the legend for Figure 1. The expected ratio of conspecific to heterospecific matings for pairs of L. idas and L. melissa populations (B). Values greater than 0 denote more conspecific than heterospecific mating events.

approached conspecific and heterospecific female wing models. These estimated differences in mate preference are sufficient to engender moderate sexual isolation (Figure 2B). Finally, mate preference varied among admixed populations.

My previous results show clear genetic and morphological (male genitalia size and to a lesser extent wing pattern elements) differences between Northern and Melissa Blue populations in the Rocky Mountains with a broad geographic transition between the character states from these parental populations across the hybrid zone in the GYA (Gompert et al. 2010). I also know that differences in host-plant use and habitat exist between these species (Scott 1986; Gompert et al. 2010). The current results suggest that differentiation is not limited to these phenotypic axes. Rather, L. idas and L. melissa differ in host plant preference and male mate preference. Both of these character differences might limit gene flow between these taxa and I will address this question in future research.

\section{ACKNOWLEDGEMENTS}

Thanks to the UW-NPS AMK research station for facilitating this research. This research was funded by a NSF DDIG grant to ZG.

\section{LiTERATURE CITED}

Barton NH, Hewitt GM. 1985. Analysis of hybrid zones. Annual Review of Ecology and Systematics 16:113-148.

Coyne JA, Orr HA. 2004. Speciation. Sunderland (MA): Sinauer Associates.

Fordyce JA, Nice CC, Forister ML, Shapiro AM. 2002. The significance of wing pattern diversity in the Laycaenidae: mate discrimination by two recently diverged species. Journal of Evolutionary Biology 15:871-879.

Forister ML, Nice CC, Fordyce JA, Gompert Z. 2009. Host range evolution is not driven by the optimization of larval performance: the case of lycadies Melissa (Lepidoptera lycanidae) and the colonization of alfalfa. Oecologia 166:551-561.

Gompert Z, Lucas LK, Fordyce JA, Forister ML, Nice CC. 2010. Secondary contact between Lycaeides idas and L. melissa in the Rocky Mountains: extensive mixture and a patchy hybrid zone. Molecular Ecology 15:31713192. 
Jiggins CD, Naisbit RE, Coe RL, Mallet J. 2001. Reproductive isolation caused by colour pattern mimicry. Nature 411:302-305.

Scott J. 1986. The Butterflies of North America: A Natural History and Field Guide. Palo Alto (CA): Stanford University Press. 